\section{O desafio da Alimentação e Nutrição}

Bertoldo Kruse Grande de Arruda **
*As idéias apresentadas incorporam sugestões do Professor Malaquias Batista Filho e do Doutor Eduardo Kertezs.

\footnotetext{
* Universidade Federal de
} Pernambuco.
A politica alimentar e nutricional brasileira deve ser considerada em três niveis de atuação:

- a nível de produção, o apoio técnico, crediticio e de mercado a cinco produtos essenciais - o feijão, o arroz, o milho, a farinha de mandioca e o leite;

- a nível de consumo, a estratégia é privilegiar a formaçẫo de estoques reguladores de alimentos básicos, a adequada armazenagem, a distribuição e comercialização que beneficie os segmentos populacionais de menor renda. Complementarmente, fortalecer e ampliar os programas institucionais dirigidos a clientelas especificas - gestantes, nutrizes, pré-escolares, escolares e trabalhadores. $\dot{E}$ defendido o subsidio para alimentos em áreas de alta densidade de pobreza, comercializados através da rede de mercado varejista;

- a nível de aproveitamento biológico, é indispensável o controle das intercorrências patológicas que podem transtornar os processos digestivos e metabólicos, reduzindo ou mesmo impedindo o aproveitamento da energia e nutrientes dos alimentos consumidos. A prioridade deve ser o combate ao sinergismo carência nutritiva/infecções.

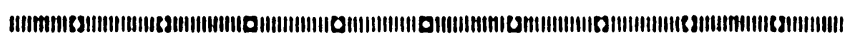

A reelaboração política e programática na área de alimentação e nutrição, no Brasil, deve considerar três aspectos críticos:

- a produção de alimentos básicos tem sido fortemente comprometida nas duas últimas décadas;

- o sistema de abastecimento (transporte, armazenagem e comercialização) complica as deficiências técnicas e econômicas do setor produtivo;

- o quadro de saúde precário da população é agravado pela interação sinérgica entre as infecções e a desnutrição.

Cadernos de Saúde Pública, R.J., 1(3): 297-304, jul/set, 1985.
Recebido para publicação em 05/03/85. 


\section{Como estimular a produção?}

No atinente ao estímulo da produção, as seguintes medidas são recomendáveis:

- a facilitação aos pequenos produtores rurais do acesso a terras agricultáveis, do emprego de práticas adequadas de cultivo e da consolidação das organizações cooperativas;

- a aplicação diferenciada de taxas de juros ao crédito destinado a estimular a produção de cinco alimentos básicos: arroz, feijão, milho, farinha de mandioca e leite. E criação de mecanismos que conduzam à utilização mais eficaz do crédito rural, exigindo maior eficiência e produtividade das culturas;

- o incentivo ao desenvolvimento e uso de tecnologias apropriadas, direcionando as pesquisas para responder às especificidades das áreas produtoras;

- o zoneamento de áreas produtoras de alimentos básicos, visando à concentração e integração dos estímulos govemamentais, assegurando pelo PROAGRO a cobertura total dos financiamentos concedidos;

- a adoção de mecanismos simplificados e adequados ao atendimento dos produtores de alimentos básicos, viabilizando o suprimento dos insumos mais indicados;

- o estabelecimento de preços remuneradores e a garantia de mercado.

A nível de produção, a estratégia para enfrentar seriamente o problema alimentar no País requer uma política de apoio a cinco produtos: o feijão, o arroz, o milho, a farinha de mandioca e o leite.

No quadro de consumo alimentar nacional, o feijão e o arroz situam-se entre as cinco principais fontes de calorias e proteínas utilizadas pela população. Constituem a base alimentar das famílias de baixa renda, pois cobrem, conforme estudo realizado em São Paulo (IPE/USP, 1981), 35\% do consumo energético e $45 \%$ do protéico, pesando $24 \%$ nos gastos com alimentação.

A importância do milho justifica-se mais pela sua função na avicultura e na suinocultura. É significativa a contribuição crescente da carne de aves e do consumo de ovos como substitutivos da carne bovina.

A farinha de mandioca é uma irrecusável prioridade regional no Norte e no Nordeste, estando entre os três produtos de consumo mais elevado. Ademais, representa a lavoura de função econômica mais importante nas áreas de atividade policultora no Nordeste. 
O leite é o suporte eletivo na dieta habitual da criança, mormente durante as agressões infecciosas, seqüenciando o período de amamentação exclusiva e fazendo parte das dietas de transição para a alimentação familiar. Cabe ponderar que a alimentação láctea de uma criança compromete de 12 a $15 \%$ do salário mínimo.

Uma estratégia para promover o estímulo da produção de alimentos básicos é o PROCAB/INAN, Projeto de Aquisição de Alimentos Básicos em Áreas Rurais de Baixa Renda, que objetiva:

- contribuir para a melhoria da renda e decorrente elevação do padrão alimentar dos pequenos produtores rurais, garantindo mercado institucional para colocação dos excedentes de sua produção a preços remuneradores;

- apoiar os pequenos produtores, mediante a concessão de capital de giro às cooperativas e companhias estaduais, para aquisição de seus produtos;

- possibilitar às administrações estaduais o desenvolvimento de linhas de apoio complementares, tais como o suprimento de insumos, a assistência técnica e demais ações que visem ao fomento da produção e melhoria da produtividade de alimentos tradicionais;

- priorizar as fontes de abastecimento regional, reduzindo elos da cadeia de comercialização e, conseqüentemente, os preços finais, concorrendo para aumentar a arrecadação de impostos estaduais.

O potencial de garantia de mercado para a comercialização de alimentos básicos através do PROCAB, tais como: arroz, feijão, farinha de mandioca, milho e leite, atinge não só os volumes de compra programados para abastecer o PNS e PROCAB, bem como a possibilidade de comercialização no mercado geral e mesmo em outros programas institucionais, como o PNAE.

\section{Como elastecer o consumo?}

Em relação ao consumo, a maneira mais legítima de assegurá-lo satisfatoriamente consiste na melhoria das condições sócio-econômicas da população: empregos e salários adequados.

$\mathrm{Na}$ base, portanto, a revisão da política de distribuição da renda. Complementarmente, $o$ incentivo ao consumo exige uma política de abastecimento que privilegie:

- a formação de estoques reguladores de alimentos básicos, de modo a controlar os preços e evitar manobras 
especulativas que agreguem custos desnecessários de comercialização;

- o dimensionamento e desempenho de uma adequada armazenagem, a nível de propriedade e nos diferentes pontos do sistema de distribuição e comercialização, para reduzir as perdas pós-colheitas e preservar corretamente os alimentos;

- o redirecionamento dos sistemas de distribuição e comercialização de alimentos, principalmente os oficiais, para que atendam às necessidades dos segmentos populacionais de menor poder aquisitivo, regularmente e sem interrupções;

- uma intensa e correta informação dos consumidores, a fim de que escolham com mais acerto preços e qualidade e evitem o desperdício.

A curto prazo, o aumento do consumo, em caráter supletivo, é obtido através de programas institucionais dirigidos a clientelas específicas. Estão sendo implementados os seguintes:

- O Programa de Nutrição em Saúde (PNS), desenvolvido pelo INAN, utiliza a rede de serviços de saúde, beneficiando os grupos biológicos e sociais mais expostos a riscos infecciosos e nutricionais (gestantes, nutrizes e crianças menores de 5 anos). Integrando a suplementação alimentar às ações básicas de saúde, potenciam-se os efeitos resultantes destas práticas. Contribui também para atrair a procura e constância das populações de mais baixa renda aos serviços.

- O Programa de Complementação Alimentar (PCA), mantido pela LBA, que beneficia clientela semelhante à atendida pelo INAN.

- O Programa Nacional de Alimentação Escolar (PNAE), executado pela FAE, complementa a alimentação de alunos matriculados na rede de escolas do 19 grau.

- O Programa de Alimentação do Trabalhador (PAT), financiado pelo Governo, empresas e trabalhadores comensais (estes com $20 \%$ do custo), fornece uma refeição diária, através de restaurantes industriais e outras formas de atendimento.

Até que alternativas melhores sejam decididas e implantadas, é recomendável o fortalecimento dos programas existentes (quadro anexo), introduzindo procedimentos que maximizam os recursos aplicados, tais como:

- estabelecer um mecanismo para a efetiva coordenação interinstitucional. Essa tarefa a legislação vigente atri- 
bui ao INAN, mas sem a contrapartida de condições para exercitá-la;

- dimensionar os recursos, em função da clientela a ser atendida e do suplemento alimentar oferecido;

- compatibilizar a liberação de recursos com a programação de compras, para pagamento à vista das aquisições, visando aos ganhos de escala e à redução de preços nas ofertas sazonais, aproveitando sempre as oportunidades de mercado;

- manter um nível adequado de supervisão, de modo a corrigir oportunamente as possíveis distorções;

- normatizar critérios uniformes e realísticos, mormente no que se refere ao acondicionamento, transporte, armazenagem e controle da qualidade dos alimentos;

- priorizar, sempre que possível, a aquisição regional, cotando preço final que inclua embalagens, empacotamento e fretes;

- redefinir o elenco de produtos distribuídos, com vistas às facilidades operacionais, respeitando os critérios econômicos e nutricionais;

- operar com cardápios flexíveis e, na ocasião das compras, levar em conta os preços relativos dos alimentos básicos e as expectativas de alta, ficando a decisão do que comprar na dependência da informação dos estoques disponíveis no País, dentro de uma política geral de abastecimento.

No caso do PNS/INAN, a opção foi reduzir para três alimentos a cesta distribuída: leite para crianças de 6 meses a 2 anos de idade, arroz e feijão para as gestantes, nutrizes e crianças de 2 a 5 anos. Uma proposta em estudo é o PNS distribuir apenas leite em pó integral e ampliar consideravelmente a população-alvo e a quantidade de leite por beneficiário. Eleger-se-ia, então, o leite como uma vacina contra a desnutrição, universalizando o atendimento a todas as crianças do País, que são as maiores vítimas da carência alimentar.

Por sua vez, a aquisição desse produto em grandes quantidades, através do PROCAB/INAN, estimulará uma atividade típica de pequenos e médios produtores, podendo estabilizar o setor leiteiro no Brasil, que vive em crise constante.

Seria o núcleo de um Programa Nacional do Leite.

Além dos programas que operam à base da distribuição gratuita de alimentos, o INAN defende e demonstra a exeqüibilidade de subsidiar alimentos para as populações de áreas de alta densidade de pobreza. É o caso do Programa 
de Abastecimento de Alimentos Básicos (PROAB), que utiliza a rede de mercado varejista existente nas periferias urbanas mais pobres das capitais nordestinas. E há justificativas para a coexistência dessas modalidades de intervenção.

$O$ PROAB fundamenta-se no reconhecimento de que a renda limitada das famílias que vivem nessas áreas representa, essencialmente, o fator restritivo do consumo.

Seu maior objetivo é oferecer a essas populações a possibilidade de comprar alimentos essenciais a preços mais acessíveis, mediante:

- a organização do sistema convencional de abastecimento, via instalação de centrais de serviço (atacado) e cadastramento dos varejistas da área nestas unidades;

- a fixação de um subsídio médio de $20 \%$ aos preços dos principais alimentos que compõem a pauta de consumo habitual;

- a fiscalização dos preços e qualidade dos alimentos pela comunidade de consumidores;

- a manutenção da prática tradicional de venda a granel, em pequenas quantidades, e da forma de pagamento;

- a concessão de benefício fiscal, por parte do Estado, às operações de venda final de varejo.

Essa metodologia permite:

- atingir direta e facilmente, com a vantagem da proximidade do domicílio, a uma grande massa popular, havendo reduzidas possibilidades de desvios quanto ao seu objetivo final;

- exigir a inscrição do varejista, legalizando suas operações comerciais;

- garantir, na venda ao atacado, via Cobal, o recolhimento do ICM incidente sobre o valor real das mercadorias até esta fase da operação;

- ao recolher o ICM no atacado, que a isenção não implique perdas para o Tesouro estadual e evite o desgaste do subsídio;

- proteger a população atendida de agressões psicológicas que decorrem do processo de seleção de pobres em seu meio;

- finalmente, viabilizar a pequena e média empresa, contrapondo-se ao aumento indesejável do nível de oligopolização dos supermercados, com sérios reflexos nos preços ao consumidor, na medida em que é conseqüência inevitável do oligopólio, uma política de preços administrados. 
$A$ influência do INAN em projetos como o PROCAB e o PROAB é estrategicamente importante, para que sejam preservados seus objetivos sociais, dentro do enfoque nutricional. A experiência brasileira e de outros países indicam uma tendência inconveniente: as áreas agrícolas e de mercado serem dominadas por objetivos exclusivistas de eficiência econômica, em benefício do pólo empresarial, colocando em instância secundária os interesses dos consumidores. Surgindo uma nova postura institucional desses projetos, faz-se míster que o INAN mantenha, de alguma forma (consultiva e deliberativa), a sua influência.

\section{Como otimizar o aproveitamento biológico?}

O último aspecto crítico a considerar é a existência de intercorrências patológicas, que podem transtornar os processos digestivos e metabólicos, reduzindo ou mesmo impedindo o aproveitamento da energia e nutrientes dos alimentos consumidos. Destarte, embora seja indispensável que os alimentos estejam disponíveis permanentemente, em todo o País, e que toda a população tenha acesso a uma cesta alimentar básica, é co-requisito, necessário para atingir-se uma boa situação nutricional, o controle das doenças que prejudicam esse aproveitamento.

$\mathrm{Na}$ prática, são as doenças infecciosas que efetivamente interferem no metabolismo e determinam a freqüência e gravidade da desnutrição. Assim, atuar contra o sinergismo carência nutritiva/infecções possibilita avanços mais rápidos no combate à desnutrição. Daí a reorientação dos programas de nutrição e saúde, proposta pelo Ministério de Saúde e consubstanciada na transferência para o INAN da coordenação da assistência materno-infantil.

Um conjunto de medidas de eficácia já comprovada e de aplicação mais simples está em execução:

- a suplementação alimentar dos grupos biológicos e sociais mais expostos aos riscos infecciosos e nutricionais;

- o diagnóstico precoce e tratamento das infecções respiratórias agudas;

- a reidratação oral, nos casos de doenças diarréicas;

- o estímulo às práticas de aleitamento materno;

- a cobertura vacinal contra as doenças imunopreveniveis;

- o tratamento das enteroparasitoses.

Estas ações têm o respaldo da assistência médica, da vigilância do crescimento e desenvolvimento e do trabalho educativo nos aspectos de saúde e nutrição. 
A reordenação político-programática em discussão deve também contemplar um conjunto de carências nutricionais específicas, relativamente fáceis de prevenir e controlar, a um custo mais baixo: uma deficiência vitamínica - a hipovitaminose $\mathrm{A}$ - e três minerais - o bócio, as anemias e a cárie dental.

Freqüentemente, a hipovitaminose $\mathrm{A}$ e as anemias nutricionais ocorrem nas mesmas condições ambientais onde incide a desnutrição energético-protéica, estando, em muitos casos, a ela associadas.

A experiência do INAN nesse campo tem se revelado promissora e até inovadora, em algumas definições operacionais, promovendo o combate ao bócio, através da iodatação do sal de consumo humano e animal, à anemia, pela administração de sais de ferro e vermífugos, e à hipovitaminose $\mathrm{A}$, aplicando doses maciças de retinol. No combate à cárie, participou com a FSESP de projeto de fluoração das águas de consumo.

Em última análise, não esquecer a redefinição do papel dos recursos humanos, procurando incentivar o trabalho interdisciplinar e a participação dos produtores e das comunidades, preparando profissionais que não vejam suas responsabilidades simplesmente em termos de descobertas científicas e da disseminação de conhecimentos.

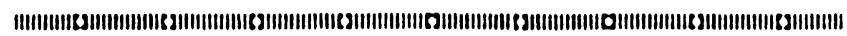

The Brazilian food and nutritional consider three levels of performance:

1) At a production level - The technical support, credit facilities and marketing to five essential products: beans, rice, corn, manioc flour and milk;

2) At a consumption level - The strategy is to develop the building up of regulating stocks of basic food, the adequate storage, the distribution and commercialization that benefits the populational segments of lowest income. Together with the strengthening and amplification of the institutional programs directed to specific customers: pregnant women, breast feeding women, pre-school children, school children and workers. It is protected the subsidy for food in areas of high poverty density, distributed through the network of retail market;

3) At a biological utilization - Is indispensable the control of pathological variations which may disturb the digestive and metabolic processes reducing or even blocking the utilization of energy and nutrients from the food eaten up. The priority must be the fight against the synergism nutritional deficiency/infections. 